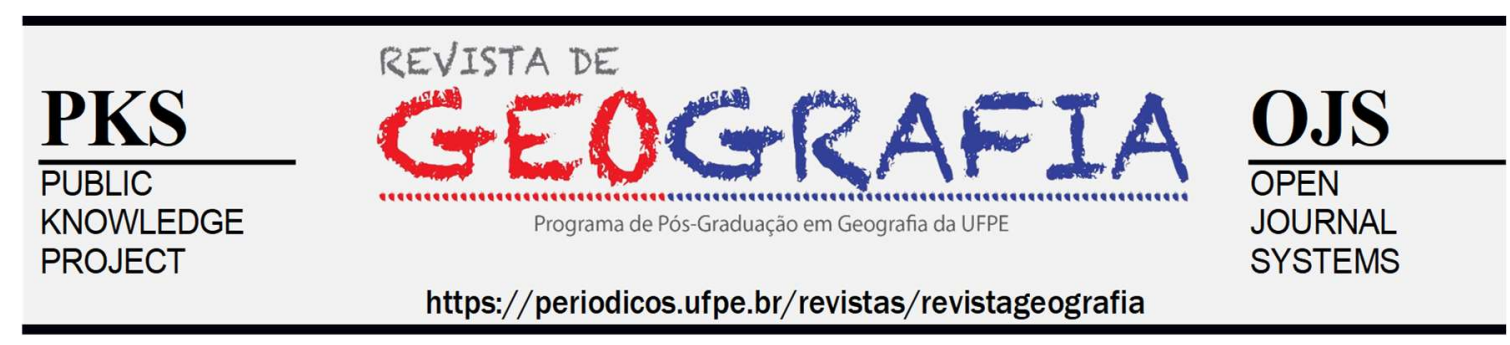

\title{
OS CAMINHOS ATÉ NIZHNY TAGIL: A CONSOLIDAÇÃO DO PATRIMÔNIO INDUSTRIAL E O SEU ESTUDO PELA GEOGRAFIA
}

\author{
Renan Caldas Galhardo Azevedo ${ }^{1}$ \\ ${ }^{I}$ Bacharel e Licenciado em Geografia pela Universidade do Estado do Rio de Janeiro - UERJ. Mestrando \\ em Geografia pela Universidade Federal do Rio de Janeiro - UFRJ. E-mail: \\ renan.azevedo08@outlook.com
}

Artigo recebido em 02/04/2020 e aceito em 01/06/2020

\begin{abstract}
RESUMO: Os Patrimônios Industriais são atualmente estudados por diversas áreas do conhecimento. Entretanto, são frutos de reflexões recentes existentes no campo de trabalhos e estudos referentes aos Patrimônios Culturais. A Geografia, assim como outras ciências, acabou contribuindo para a sua consolidação. Entretanto, a sua parcela de contribuição poderia ser maior, visto que os conceitos estudados pela ciência geográfica poderiam auxiliar ainda mais no desenvolvimento das discussões sobre o tema. Nesse sentido, o presente trabalho visa demonstrar como fora o caminho até a consolidação do que hoje entendemos como Patrimônio Industrial - passando pela noção de Patrimônio Cultural - e como a Geografia vem abordando este tema ao longo das últimas décadas.
\end{abstract}

Palavras-chave: Patrimônio Industrial; Patrimônio Cultural; Geografia.

\section{THE PATHS TO NIZHNY TAGIL: THE CONSOLIDATION OF INDUSTRIAL HERITAGE AND ITS STUDY IN GEOGRAPHY}

\begin{abstract}
Industrial Heritage is currently studied by several areas of knowledge. However, they are the fruit of recent reflections in the field of works and studies related to Cultural Heritage. Geography, like other sciences, ended up contributing to its consolidation. However, their share of contribution could be greater, since the concepts studied by Geography could contribute even more to the development of discussions on the topic. In this sense, the present work aims to demonstrate how the path until the consolidation of what we understand today as Industrial Heritage - passing through the notion of Cultural Heritage - and how Geography has been approaching this theme over the last decades.
\end{abstract}

Keywords: Industrial Heritage; Cultural Heritage; Geography. 


\section{INTRODUÇÃO}

O entendimento atual sobre Patrimônios Culturais é um produto resultante de diferentes discussões e propostas discorridas sobre o tema ao longo dos últimos séculos, envolvendo diferentes estudiosos e pesquisadores filiados às mais diversas áreas do conhecimento. Se a priori a noção de Patrimônio esteve relacionada diretamente aos Monumentos Históricos (CHOAY, 2000), o século XX trouxe à tona contribuições que forneceram novas e importantes interpretações sobre aquela, principalmente nos anos posteriores à Segunda Guerra Mundial. A partir deste momento a noção de Patrimônio ganha uma nova interpretação e passa a estar relacionada também aos inúmeros tipos de bens materiais e imateriais ligados a diferentes culturas existentes, interpretação esta que forneceu subsídios para a consolidação da noção que hoje entendemos como Patrimônio Cultural (FUNARI e PELEGRINI, 2009). Foi neste contexto que novas tipologias patrimoniais surgiram, o que inclui aquela que atualmente denominamos de Patrimônio Industrial.

Nesta perspectiva, o presente trabalho visa demonstrar, a partir do resgate de importantes referências bibliográficas, como fora a trajetória até a consolidação do que hoje entendemos como Patrimônio Industrial e como o mesmo foi estudado pela Geografia ao longo das últimas décadas. Assim, dividiremos o nosso trabalho em três partes: na primeira resgataremos como a noção de Patrimônio Cultural surgiu em meio às discussões sobre a proteção, a conservação e o restauro dos Patrimônios Históricos durante o século XX. Em seguida, demonstraremos como a tipologia denominada de Patrimônio Industrial emerge e se consolida no período pós guerra, tendo como ápices o reconhecimento do termo pela UNESCO (1972) e, algumas décadas mais tarde, a publicação da Carta de Proteção ao Patrimônio Industrial (2003). Por fim, analisaremos como os Patrimônios Industriais foram estudados pela Geografia, fazendo uma espécie de "estado da arte" do tema na ciência escolhida, além de indicar brevemente os possíveis caminhos para aqueles que desejam ingressar com o tema em seus estudos.

\section{DOS MONUMENTOS HISTÓRICOS AOS PATRIMÔNIOS CULTURAIS}


Sendo vistos inicialmente como remanescentes e representantes da Antiguidade, os Monumentos Históricos, "embriões" do que hoje entendemos como Patrimônios Culturais, já despertavam o interesse de diferentes estudiosos - principalmente dos humanistas - no século XV (CHOAY, 2000). Tais Monumentos eram naquele momento entendidos como importantes fontes documentais ${ }^{1}$ que ajudavam a recontar a história das sociedades que os produziram, história esta que se perdia com a passagem do tempo (FUNARI e PELEGRINI, 2009). Por este motivo os estudiosos que se debruçavam sobre o tema exigiam que aqueles bens fossem não somente conhecidos pela sociedade como também preservados.

Apesar dos avanços ocorridos sobre o campo de estudos dos Monumentos Históricos nos séculos seguintes, o processo de industrialização e a Revolução Francesa acabaram sendo vistos como duas grandes ameaças aos bens que representavam o passado humano (CHOAY, 2000). A instalação de fábricas e indústrias decorrentes do processo de industrialização provocou, em inúmeros casos, uma série de destruições sobre diferentes recortes espaciais existentes. Essas reformulações de lugares, como diria Harvey (2011), tinham frequentemente o aval dos Estados - principalmente do Estado Moderno que surgia naquele momento - pois estavam associadas às ideias de "progresso" e de "avanço da Modernidade" sobre espaços ditos como "obsoletos". Todavia, eram reformulações espaciais que acabavam atingindo diretamente diferentes tipos de lugares, o que inclui aqueles que possuíam em sua composição Monumentos Históricos de grande valor cultural e que ajudavam a recontar a história de diferentes sociedades.

A Revolução Francesa, não muito diferente do processo de industrialização ocorrido em diferentes nações europeias, acabou tendo também capítulos de destruição generalizada em diferentes sentidos. Os revolucionários desejavam apagar todos os traços que ligavam o povo ao Antigo Regime, que havia sido derrubado naquele momento na França. Tal ação acabara por facilitar não somente o saque como a destruição de diferentes tipos de bens móveis e imóveis presentes no país e que eram diretamente

\footnotetext{
${ }^{1}$ Tanto Choay (2000) como Funari e Pelegrini (2009) argumentam que os estudiosos da Antiguidade preferiam estudar os Monumentos Históricos porque era menos plausível que estes enganassem àqueles que os estudassem. Bem diferente dos livros, que poderiam ser somente cópias ditas como originais por aqueles que os tinham.
} 
ligados à coroa. Aqui podemos incluir também o saque e a destruição de antigos Monumentos Históricos (CHOAY, 2000).

Os acontecimentos citados contribuíram para que diferentes estudiosos ligados à diversas áreas do conhecimento reivindicassem aos Estados dos quais faziam parte ações políticas voltadas à proteção e à conservação dos Monumentos Históricos, medidas estas preventivas, buscando defender os bens que ainda não tivessem sido alvo de destruições e de possíveis danos irreparáveis.

A França, após a perda de alguns de seus bens, acabou sendo o primeiro país a adotar uma série de ações visando à proteção dos seus Monumentos. Num primeiro momento o governo francês criou uma comissão encarregada de proteger os bens. Posteriormente, de forma complementar, criou uma legislação voltada diretamente à conservação e à restauração dos Monumentos Históricos presentes em seu território (FUNARI e PELEGRINI, 2009). Essas ações ajudaram a fazer com que os Monumentos passassem a serem vistos como Patrimônios da nação francesa, bens que deveriam ser resguardados para as futuras gerações a fim de representar a memória da França enquanto Estado-nação. Nesse sentido, é possível dizer que o Estado Moderno contribuiu para a consolidação do que hoje entendemos como Patrimônio Histórico (FONSECA, 2005)².

Com o fim do século XIX e a chegada do século XX, a noção de Patrimônio Histórico se dissemina e acaba sendo adotada por diferentes países, tais como a Itália e a Áustria (CHOAY, 2000; FUNARI e PELEGRINI, 2009). Todavia, as discussões sobre o tema não cessaram, visto que o século XX trouxera novos desafios quanto à proteção, à conservação e à restauração dos bens. As políticas urbanas existentes na Europa, baseadas na destruição de vários tipos de formas urbanas buscando a "higienização" e a "modernização" das cidades (FOLLIS, 2004), ameaçavam diretamente a existência dos

\footnotetext{
${ }^{2}$ É importante notar que, apesar do surgimento da noção de Patrimônio Histórico, a ideia de Monumento Histórico não deixa de existir. São noções que passam então a coexistir. Diferentes documentos produzidos para a salvaguarda de bens patrimoniais citam a ideia de Monumento Histórico e isso inclui a Convenção sobre a Proteção do Patrimônio Mundial, Cultural e Natural da UNESCO (1972), que veremos mais à frente.
} 
Patrimônios (CHOAY, 2000) $)^{3}$. Entretanto, esta ameaça seria um tanto menor frente a dois eventos que marcaram o século XX: a Primeira e a Segunda Guerra Mundial (FUNARI e PELEGRINI, 2009). As destruições causadas pela Primeira Guerra Mundial trouxeram enormes danos aos bens patrimoniais existentes em grande parte do continente europeu. Tal fato fez com que os estudiosos do tema buscassem ações mais eficientes em prol da proteção, do restauro e da conservação dos Patrimônios Históricos existentes frente às perdas ocorridas.

A Carta de Atenas (1931), documento produzido pelo Escritório Internacional dos Museus da Sociedade das Nações ${ }^{4}$, acabou sendo importante nesse sentido, visto que foi uma das primeiras tentativas de produzir, em nível internacional, uma espécie de diretriz para salvaguardar os Patrimônios Históricos (SOCIEDADE DAS NAÇÕES apud CURY, 2000). No entanto, a ocorrência da Segunda Guerra Mundial acabou interrompendo momentaneamente o avanço da proposta. Somente com o fim do conflito em 1945 que a discussão foi retomada, pois se tornou "peremptória a reconstrução das cidades e a restauração dos monumentos" (FUNARI e PELEGRINI, 2009, p. 31) frente aos grandes danos causados pela guerra. $\mathrm{O}$ temor de uma nova guerra mundial também alimentava tal ação, já que a eminência de outro conflito entre países poderia significar mais perdas irreparáveis. Por este motivo era preciso buscar soluções para a proteção dos Patrimônios frente a um futuro ainda incerto.

Na década de 1950 a campanha internacional da Organização das Nações Unidas para a Educação, a Ciência e a Cultura, a UNESCO ${ }^{5}$, visando à proteção dos templos de Abu Simbel e Philae, no Egito, foi um importante passo na tentativa de estabelecer um diálogo entre países para a salvaguarda de bens de expressivo valor para a humanidade. Os templos seriam afetados pela construção de uma represa e foi somente com o estabelecimento de uma espécie de ajuda mútua entre diferentes Estados que os bens

\footnotetext{
${ }^{3}$ Os projetos de Haussmann na França são o maior exemplo. Resultaram em reformas que acabaram destruindo boa parte das formas urbanas de Paris e influenciaram reformas urbanas por todo o mundo, inclusive no Brasil (FOLLIS, 2004).

${ }^{4}$ Também conhecida como Liga das Nações, organismo precedente à Organização das Nações Unidas (ONU).

${ }^{5}$ United Nations Educational Scientific and Cultural Organization.
} 
puderam ser deslocados do local em que estavam para outro mais seguro (LEAL, 2010). O sucesso da ação demonstrou que era possível estabelecer um elo entre países no sentido de proteger os Patrimônios Históricos em nível global, servindo como uma espécie de "ensaio" para o que viria a ocorrer em um futuro não muito distante.

Alguns anos mais tarde a Carta de Veneza (1964), produzida pelo II Congresso Internacional de Arquitetos e Técnicos dos Monumentos Históricos, retomou parte das propostas da Carta de Atenas (1931) e da própria campanha da UNESCO no Egito. O documento criado no Congresso tinha como fundamento a necessidade de proteger e restaurar os bens da Antiguidade, entendendo-os como testemunhos do passado humano que representavam variadas culturas que existiram no planeta. Assim, estabelecia uma ajuda mútua entre os signatários do documento em benefício desses bens que representavam a própria humanidade (ICOMOS apud CURY, 2000). Dessa forma, os responsáveis pelo documento propõem naquele momento aos seus assinantes algumas diretrizes a serem seguidas em prol da defesa dos Patrimônios Históricos em nível internacional.

Além de concretizar o retorno de uma proposta importante, a Carta de Veneza foi também um dos primeiros documentos a explorar a relação entre a noção de Patrimônio e o conceito de Cultura. O momento no qual foi desenvolvida - década de 1960 - é marcado pela luta de reconhecimento dos direitos civis de diferentes culturas e grupos sociais ao redor do globo (FUNARI e PELEGRINI, 2009), o que fez com que a noção de Patrimônio defendida pelos criadores da Carta começasse a abranger também, mesmo que de forma vagarosa, os diferentes bens não somente históricos, como também culturais pertencentes às nações. Assim, a noção de Patrimônio Cultural já passava a permear os documentos que abrangiam a defesa dos Patrimônios. Um passo enorme que ajudaria futuramente no reconhecimento de novas tipologias patrimoniais.

Outros eventos em prol dos Patrimônios Históricos ocorreram após a publicação da Carta de Veneza buscando contribuir ainda mais com a proposta estabelecida por ela. Todavia, somente no ano de 1972 a proposta de proteger tais bens em nível internacional entraria em voga de forma definitiva. Durante a décima sétima sessão anual da UNESCO ocorre a homologação da Convenção para a Proteção do Patrimônio Mundial, Cultural e 
Natural. Este documento estabelece o que era objetivado há décadas por aqueles que trabalhavam no campo de pesquisas patrimonial: a construção de um sistema internacional buscando a proteção, o restauro e a conservação de diferentes bens relacionados à história, à cultura e à natureza de diferentes países existentes pelo mundo (UNESCO, 1972). Além de estimular ações buscando a salvaguarda de distintos bens em nível internacional, a Convenção de 1972 fez com que os Estados signatários do documento reconhecessem a importância de preservar seus próprios bens. Assim, determinou que os países participantes da Convenção criassem seus próprios sistemas nacionais de proteção, conservação e restauro, além de exigir que os mesmos fossem respaldados jurídica e cientificamente. Aqueles que seguiam os passos determinados pela UNESCO poderiam então candidatar seus Patrimônios à lista de bens reconhecidos como Patrimônios Mundiais (Ibidem, 1972), o que conferia ao bem maior grau de importância e proteção frente aos demais tipos de tombamentos existentes (LEAL, 2010).

Por fim - o que é mais importante aqui, sem dúvida - a Convenção de 1972 concretizou também a noção de Cultura nas discussões sobre os Patrimônios, entendendo que diferentes bens associados à diferentes culturas e grupos sociais poderiam assim ser amparados pela noção, o que acabou universalizando a proposta até então existente. Uma ação que reafirma o quanto o documento estava alinhado com as questões do momento, ao se deparar com um mundo onde diferentes tipos de culturas e grupos sociais reivindicavam o reconhecimento de suas lutas e de seus bens perante às sociedades. Assim, como diz Oliveira (2017, p. 313),

[...] com a universalização dos valores ocidentais sobre o patrimônio no Século XX, não apenas se justificou a instauração de órgãos de proteção patrimonial, como também se reformulou diretrizes e difundiu novas tipologias patrimoniais (arqueológica, científica, popular ou industrial).

Nessa perspectiva, devemos entender que foi a partir da Convenção de 1972 que novas tipologias patrimoniais passaram a serem reconhecidas no cenário mundial. Afinal, foi somente por meio do desenvolvimento do conceito de cultura e do estabelecimento da noção de Patrimônio Cultural, noção está "universalizante” (KUHL, 2010), que foi 
possível reconhecer outros tipos de bens enquanto Patrimônios, o que inclui aqui os Patrimônios Industriais.

\section{DA REVOLUÇÃO AO PATRIMÔNIO INDUSTRIAL}

O processo de industrialização surgido inicialmente na Europa a partir da Primeira Revolução Industrial inaugurou sobre o mundo um novo tipo de relação não antes vista entre os seres humanos e o planeta. Novos métodos produtivos, novas técnicas, novos tipos de relações de trabalho... Inúmeras foram as novidades tragas por este processo que, ainda no século XIX, experimenta o seu segundo momento de intensidade: a Segunda Revolução Industrial.

Com a passagem do tempo alguns estudos surgiram tendo como foco o processo de industrialização, os espaços onde as produções industriais ocorriam e os trabalhadores associados ao processo. Estes estudos acabaram se concentrando em dois tipos: aqueles que criticavam a forma tal qual o processo ocorria, como o estudo produzido por Engels (2010) e o ensaio de Lafargue (2016); e aqueles que viam tal processo como benéfico e buscavam contribuir com novas teorias para o aumento das produções já existentes (CARMO, 2005). Demoraria certo tempo para que o processo de industrialização ocorrido em diversos países fosse analisado de outras formas possíveis.

Da mesma forma que afetaram os Patrimônios Históricos existentes, a Primeira e a Segunda Guerra Mundiais trouxeram danos bastante significativos aos diferentes espaços produtivos que compunham a economia nacional dos Estados presentes principalmente na Europa (ROSA, 2011). Muitas localidades ligadas tanto à Primeira como à Segunda Revolução Industrial acabaram sendo destruídas, o que contribuiu para a perda - em definitivo - de bens e modos de vida ligados ao modelo industrial existentes.

Associado às perdas ocorridas durante as duas grande guerras mundiais, o período pós guerra também foi acompanhado pelo processo de desindustrialização, que passou a atingir países europeus como, por exemplo, a Inglaterra (MENGUELLO, 2011). Assim, os destinos de indústrias, fábricas, minas e até mesmo de canais, ferrovias e 
estações de trem - todos ligados ao processo de industrialização e às Revoluções Industriais ocorridas no continente - tornaram-se incertos, pois eram vistos como espaços obsoletos que não tinham o mesmo uso de antes. Era preciso se adequar às "necessidades" do momento.

Todos os fatos anteriormente mencionados começaram a suscitar no meio acadêmico a necessidade de levar em consideração a importância de preservar os antigos espaços ligados à produção industrial (e de todos os bens e processos tangíveis e intangíveis associados àqueles), pois não demoraria muito para que tais recortes espaciais - e suas devidas marcas - fossem perdidos definitivamente frente às rápidas mudanças socioeconômicas que estavam ocorrendo naquele momento na Europa e que facilmente acabaria atingindo outras localidades do globo.

O pesquisador britânico Michael Rix foi um dos primeiros estudiosos a se solidarizar com o tema (ROSA, 2011), chamando a atenção da Academia para a necessidade de conservar os antigos bens industriais em um artigo intitulado Industrial Archaeology publicado na revista The Amateur Historian. Em seu trabalho, Rix demonstra o quanto a Grã-Bretanha ainda possuía em seu território uma grande quantidade de bens relacionados ao processo de industrialização ligados às Revoluções Industriais ocorridas no continente europeu. Todavia, estes bens eram totalmente negligenciados pela sociedade britânica a ponto de serem destruídos sem que ninguém buscasse preservá-los (RIX, 1955). Ou seja, por mais que fossem pouco explorados cientificamente até aquele momento, o panorama poderia mudar com o apoio da Academia, que passaria a estudá-los. Isso contribuiria para a constituição de um novo campo de estudos sobre os antigos bens industriais e, ao mesmo tempo, estimularia uma espécie de preservação e conservação dos mesmos.

O argumento de Rix não foi logo aceito, visto que ainda era difícil para a compreensão de muitos pesquisadores a possibilidade de criar um campo de pesquisas para estudar antigas fábricas, indústrias e outros tipos de bens associados à industrialização ocorrida no Reino Unido. Todavia, apesar dos obstáculos encontrados inicialmente por Rix, o apelo do pesquisador acabou sendo escutado alguns anos mais 
tarde. Em 1959 o Conselho Britânico de Arqueologia ${ }^{6}$ decidiu abrir as discussões sobre o tema promovendo a primeira reunião para tratar sobre os bens industriais ainda existentes no território britânico. O resultado deste encontro foi o aceite de seus membros para a produção de um recenseamento sobre os antigos bens industriais presentes nos territórios pertencentes à coroa britânica, identificando aqueles que tinham maior valor e que assim deveriam ser estudados e preservados (ROSA, 2011).

Até aquele momento a tipologia "Patrimônio Industrial" não existia da forma que hoje conhecemos. Os escritos de Rix e os resultados obtidos pelo autor em tão pouco tempo foram ações precedentes ao estabelecimento do que viria a ser entendido como Patrimônio Industrial. O marco que "fundaria" o termo seria a luta contra a demolição do Arco de Euston, em Londres, no ano de 1961 (Ibidem, 2011). Construído em estilo dórico no ano de 1837, o Arco fazia parte da entrada da estação ferroviária de Euston, tendo sido produzido no contexto da Revolução Industrial. Logo, era um importante símbolo local sobre a paisagem londrina que representava o processo de industrialização ocorrido na Grã-Bretanha e que já fazia parte do quotidiano da cidade há mais de um século. $\mathrm{O}$ argumento que fundamentava a sua demolição era a necessidade de modernização da estação de trem frente ao novo momento em que se encontrava Londres. Assim, a ideia era expandir a estação para que pudesse comportar mais usuários, absorvendo uma maior quantidade de pessoas que poderiam se beneficiar do modal existente (RAMOS, 2017).

Apesar das manifestações públicas contra a sua demolição, o Arco de Euston acabou sendo demolido em 1961 (ROSA, 2011), o que representou uma grande perda não somente para cidade onde se localizava como para toda a Grã-Bretanha. Esse ato acabou fortalecendo o argumento de Rix sobre a necessidade de estabelecer uma proteção aos antigos bens industriais ainda existentes no Reino Unido antes que o destino dos demais bens fosse o mesmo do Arco. A partir de então a proposta de recensear os antigos bens industriais - determinada pelo Conselho Britânico de Arqueologia em 1959 - foi posta definitivamente em prática. E o termo "Patrimônio Industrial" surgiu neste momento, estando presente nos documentos que norteavam o recenseamento (MISATO e ZANIRATO, 2013). Tais fatos fizeram com que o Reino Unido fosse pioneiro em estudos

\footnotetext{
${ }^{6}$ Council for British Archaeology.
} 
e ações de preservação de antigos bens industriais, além de tornar a década de 1960 marcada pelo surgimento da nova tipologia patrimonial.

Entretanto, é importante pontuar que o surgimento do termo "Patrimônio Industrial" não garantiu o seu reconhecimento de imediato por todos aqueles que já trabalhavam no campo patrimonial. A luta pelo Arco de Euston foi somente o primeiro passo em direção a uma conquista ainda maior que estaria por vir. Vale notar que a ação popular em defesa do Arco se encaixa nas lutas por direitos civis existentes na década 1960 que forneceram subsídios para que a noção de Cultura começasse a surgir nos debates sobre Patrimônios existentes (FUNARI e PELEGRINI, 2009).

Com o passar do tempo as discussões sobre a preservação dos bens industriais avançaram e acabaram conquistando novos adeptos. Nesse sentido, o ano de 1973 ficaria marcado pela ocorrência da primeira reunião internacional sobre os Patrimônios Industriais: o $1^{\mathrm{o}}$ Congresso Internacional para a Conservação dos Monumentos Industriais ${ }^{7}$. Realizado no museu de Ironbridge Gorge, no Reino Unido, tal evento tornou-se um marco na história da tipologia que tentava se consolidar não somente por ser o primeiro dedicado aos antigos bens industriais, mas por também contar com a presença de pesquisadores filiados a inúmeras áreas do conhecimento provenientes de vários países, tendo assim representantes da Suécia, da França e dos Estados Unidos (ROSA, 2011). Esse evento acabou demonstrando o quanto o interesse pela nova tipologia se disseminou para além do Reino Unido em tão pouco tempo. O sucesso da reunião permitiu que novos encontros internacionais em prol da conservação e dos estudos sobre os antigos bens industriais ocorressem ainda durante a década 1970 (Ibidem, 2011). E seria no ano de 1978 que ocorreriam dois eventos em escala internacional extremamente importantes para o estabelecimento da noção de Patrimônio Industrial no campo patrimonial: o $3^{\circ}$ Congresso Internacional para a Conservação dos Monumentos Industriais e a reunião anual do Comitê do Patrimônio Mundial da UNESCO.

\footnotetext{
${ }^{7}$ First International Conference on the Conservation of Industrial Monuments.
} 
O $3^{\circ}$ Congresso Internacional para a Conservação dos Monumentos Industriais realizado em Estocolmo, na Suécia, acabou se tornando a mais importante reunião ocorrida até aquele momento sobre o tema por estabelecer o surgimento da primeira entidade internacional voltada à defesa dos Patrimônios Industriais: o Comitê Internacional para a Conservação do Patrimônio Industrial, também conhecido como $\mathrm{TICCIH}^{8}$. A partir do estabelecimento do comitê houve o reconhecimento em caráter definitivo do termo Patrimônio Industrial perante seus membros, além de se formalizar um grupo encarregado de auxiliar nos mais diversos tipos de assuntos relacionados aos Patrimônios Industriais (DEZEN-KEMPTER, 2007). Toda essa sistematização fizera com que a tipologia ganhasse um novo status e alcançasse um novo patamar, não demorando muito para que o seu reconhecimento se tornasse ainda maior. E foi isto o que ocorreu.

A segunda sessão da reunião anual do Comitê do Patrimônio Mundial da UNESCO, ocorrida também em 1978, trouxe uma importante conquista para aqueles que já defendiam os Patrimônios Industriais há algum tempo. As minas de sal de Wieliczka, localizadas na Polônia, foram reconhecidas como Patrimônio Mundial. O reconhecimento das minas acabou marcando a história dos Patrimônios por ser o primeiro Patrimônio Industrial a estar presente na lista dos bens reconhecidos internacionalmente pela UNESCO. Uma conquista que acabou formalizando, em nível internacional, o reconhecimento dos Patrimônios Industriais frente às demais tipologias patrimoniais já existentes.

É importante notar que tal fato só pôde se consolidar devido à universalização ocorrida sobre a noção de Patrimônio a partir do estabelecimento da ideia de Patrimônio Cultural pela UNESCO em 1972. Ou seja, se não fosse a ação daquela organização em prol do reconhecimento de diferentes bens culturais dificilmente as novas tipologias patrimoniais seriam reconhecidas (KUHL, 2010). Logo, não foi por acaso que escolhemos iniciar este trabalho recontando o passo a passo - de forma extremamente resumida - para o estabelecimento daquilo que hoje denominamos de Patrimônio Cultural.

\footnotetext{
${ }^{8}$ The International Committee for the Conservation of the Industrial Heritage - TICCIH.
} 
A partir de então a noção de Patrimônio Industrial se consolidou de vez, sendo reconhecida e adotada por diversos países. Todavia, esses fatos não significaram o fim das ações em prol dos bens industriais. Ao contrário, os trabalhos do TICCIH continuaram de forma a expandir as discussões sobre o tema. Houve assim a formalização de uma agenda de reuniões internacionais do Comitê - separadas por um curto período de anos além do surgimento de diferentes linhas de pesquisa englobando os Patrimônios Industriais nas últimas décadas de século XX. Dentre as linhas de pesquisas surgidas podemos citar: os trabalhos que buscavam o resgate e a conservação da memória relacionada ao trabalho e aos trabalhadores que viveram em fábricas, indústrias, ferrovias, minas e outros tipos de espaços ligados ao processo de industrialização ocorridos pelo mundo; pesquisas arqueológicas e em acervos visando a obtenção de documentos e materiais que fornecessem detalhes sobre as técnicas utilizadas nos processos produtivos e sobre os tipos bens produzidos; por fim, houve o aprofundamento de pesquisas focadas na composição arquitetural dos bens industriais e as suas relações com as paisagens nas quais estavam inseridos (MENGUELLO, 2011). Esses avanços permitiram que novos bens fossem reconhecidos como Patrimônios Industriais em seus devidos países, além de fornecerem subsídios para que outros bens industriais fossem reconhecidos como Patrimônios Mundiais.

Entretanto, o alto grau de complexidade alcançado nas discussões sobre o tema acabou incrementando ainda mais a preocupação sobre a preservação dos antigos bens industriais. Afinal, nem sempre a forma como os Patrimônios Industriais eram tombados garantia a sua total preservação, ou seja, o processo não era realizado da maneira mais adequada. Surge então, nos debates do TICCIH, a necessidade de elaborar um documento para auxiliar no tombamento dos antigos bens industriais em nível internacional. Nesse sentido, no ano de 2003, durante a XII Conferência Internacional do TICCIH, surge aquele que viria a ser o principal documento para a proteção dos Patrimônios Industriais existentes no mundo: a Carta de Proteção ao Patrimônio Industrial ou Carta de Nizhny Tagil (TICCIH, 2003).

Produzida na cidade russa de mesmo nome, a Carta teve como base outros documentos patrimoniais já reconhecidos, como a Carta de Veneza. Todavia, sendo 
inteiramente voltada à preservação de Patrimônios Industriais, acabou estabelecendo diretrizes básicas importantes buscando a preservação material e imaterial dos Patrimônios Industriais frente às possíveis práticas levianas de preservação existentes que poderiam comprometer a sua existência (Ibidem, 2003). O restauro, a conservação, a proteção e o uso científico e social desses bens estiveram no centro das diretrizes determinadas pelo documento, assegurando assim a defesa dos Patrimônios Industriais frente aos diferentes processos socioeconômicos que poderiam afetá-los.

Outras conferências posteriormente ocorridas adicionaram diretrizes complementares ao documento, preenchendo as possíveis lacunas existentes. Entretanto, nada que afetasse profundamente as propostas anteriormente estabelecidas pelo TICCIH. Assim, a Carta tornou-se o documento oficial do Comitê, norteadora de práticas de conservação, preservação e restauro dos antigos bens industriais, marcando a história da tipologia no campo de trabalhos e pesquisas sobre os Patrimônios Culturais.

Se de início Michael Rix encontrava dificuldades em demonstrar o quanto era necessário preservar fábricas, indústrias, minas, ferrovias e outros tantos recortes espaciais vinculados aos antigos processos industriais, hoje o panorama é diferente. Existe todo um respaldo técnico e científico para a proteção de tais bens em nível internacional, respaldo este que existe graças à universalização da noção de Patrimônio Cultural ocorrida a partir da Convenção da UNESCO de 1972.

\section{O PATRIMÔNIO INDUSTRIAL E O SEU ESTUDO PELA GEOGRAFIA}

Diferentes áreas do conhecimento ajudaram no avanço das discussões sobre os Patrimônios Industriais a partir da produção de trabalhos e estudos científicos que forneceram subsídios para o seu reconhecimento em nível internacional. A Arqueologia, a História e a Sociologia foram áreas importantes neste sentido (KUHL, 2010). A Geografia, no entanto, não se figurou como uma das áreas do conhecimento que contribuíram para os avanços das pesquisas sobre o tema. Ela teve (e ainda tem) uma participação muito pequena no que tange à noção de Patrimônio Industrial. 
$\mathrm{Na}$ literatura internacional existem trabalhos que tratam da relação entre Geografia e Patrimônio Industrial de forma bastante superficial, como é o caso da obra produzida por Graham, Ashworth e Tunbridge (2000), que dedica poucas páginas ao tema. Entretanto, há também estudos mais profundos produzidos principalmente após os anos 1990 nos quais pesquisadores filiados à Geografia exploram diferentes pontos de vistas na relação entre Geografia e Patrimônio Industrial. Nesse sentido, é possível encontrar trabalhos que versam sobre: 1) os tipos de refuncionalizações ocorridas nos antigos bens industriais tombados; 2) os seus variados usos relacionados ao Turismo; 3) a relação entre Patrimônio Industrial e Meio Ambiente; e 4) o quanto os Patrimônios Industriais podem ser entendidos enquanto lugares que resguardam sentimentos, identidades e memórias pertencentes ao trabalho e aos trabalhadores que tiveram suas vidas afetadas pelos bens industriais.

Nos estudos sobre a refuncionalização de antigas fábricas e indústrias e a sua conversão para Patrimônios Industriais o destaque fica por conta do artigo de Capel (1996). O geógrafo espanhol reflete sobre a forma como ocorreram as refuncionalizações de diferentes espaços produtivos nas décadas que precederam a produção de seu trabalho e discute sobre as estratégias existentes para a defesa desses bens, principalmente no continente europeu.

Nas pesquisas que envolvem a relação entre Geografia, Patrimônio Industrial e Turismo a lista de trabalhos se torna mais extensa e densa. O artigo de Abad (2004), por exemplo, debate sobre as diferentes possibilidades de usos turísticos existentes para os Patrimônios Industriais a partir da refuncionalização dos mesmos e reflete sobre o que hoje é denominado de "turismo industrial". Já o trabalho de Jonsen-Verbeke (1999) versa sobre a desativação das antigas minas em Limbur, na Bélgica. Ao serem desativadas, essas minas se tornaram um problema não somente ambiental como social por provocar o desemprego em massa da população local. Uma das saídas encontradas foi estabelecer um diálogo a fim de reconhecê-las como Patrimônio Industrial e torná-las um importante atrativo turístico que pudesse aliviar economicamente a região. A autora discorre assim sobre algumas possibilidades de uso e exploração das minas enquanto ponto turístico a partir de outros modelos existentes já aplicados no continente europeu. Por fim, podemos 
citar os autores Edward e Coit (1996), que discutem o uso turístico de Patrimônios Industriais relacionados a antigas áreas de mineração e concluem o seu trabalho com uma espécie de análise comparativa entre dois casos: um no País de Gales e outro na Espanha.

Quanto à relação entre Geografia, Patrimônio Industrial e Meio Ambiente, o estudo de Rudd e Davis (1998) acaba sendo um exemplo. Neste trabalho os autores analisam como a empresa Kennecott Utah Copper Corporation utilizava de atividades turísticas sobre a mina de Bingham Canyon, localizada em Utah, nos Estados Unidos mina esta reconhecida como Patrimônio Industrial e que ainda se encontrava em atividade - para esconder e possivelmente mitigar os problemas ambientais gerados pela própria empresa de mineração na localidade em que estava inserida.

Por fim, na relação entre Geografia, Patrimônio Industrial e lugares de identidades e memórias laborais, os trabalhos de Pozo e González (2012) e de Pozo (2002) são exemplos. Pozo e González (2012) demonstram como os Patrimônios Industriais passaram a serem reconhecidos na Espanha, a partir dos anos 1980, e como houvera um descompasso entre a transformação dos antigos bens industriais em Patrimônios Industriais e a aceitação da população local sobre a patrimonialização dos bens, já que, em alguns casos, houvera a não admissão dos grupos sociais sobre a sua ligação para com os bens tombados. Já Pozo (2002) escreve sobre a relação entre Geografia Cultural e Patrimônio Industrial discutindo o quanto estes bens podem ser entendidos enquanto lugares de identidade e memória coletiva e o quanto os geógrafos contribuíram para este tipo de interpretação.

Em nível nacional, o número de trabalhos sobre Patrimônio Industrial produzidos por pesquisadores filiados à Geografia é muito escasso, sendo difícil encontrar escritos sobre o tema até mesmo nos repositórios de teses e dissertações dos Programas de Pós-Graduação em Geografia do país. O trabalho de Simoni Scifoni (2017) sobre a participação social no tombamento da vila operária Maria Zélia, localizada em São Paulo - SP, é uma rara exceção, o que demonstra um certo desinteresse do tema na Geografia brasileira. Acreditamos que esse panorama possa ser mudado. 


\section{CONSIDERAÇÕES FINAIS}

A consolidação da noção de Patrimônio Cultural durante os anos 1970 permitiu que novas tipologias patrimoniais fossem reconhecidas em nível internacional, como foi o caso da noção de Patrimônio Industrial. Logo, bastaram duas décadas para que a UNESCO e o TICCIH reconhecessem a nova tipologia surgida durante as discussões sobre a preservação dos antigos bens industriais na Grã-Bretanha. A Carta de Nizhny Tagil, de forma complementar, demonstrou a necessidade de produzir melhores documentos a fim de proteger os antigos bens industriais em nível internacional, ação esta que acabou demonstrando a importância de se discutir o tema frente às demais tipologias patrimoniais existentes.

Apesar da relevância do tema e do auxílio de diferentes áreas do conhecimento para o estabelecimento e consolidação dos Patrimônios Industriais no mundo, a Geografia - de forma diferente - não contribuiu de forma exponencial para o avanço nas discussões sobre os bens industriais. A pouca presença de estudos sobre Patrimônios Industriais na Disciplina demonstra um certo desinteresse dos pesquisadores da área sobre a temática. Entretanto, é mister notar que a abordagem geográfica, a partir do uso de seus conceitoschave, poderia contribuir para avanços nos estudos sobre o tema.

O conceito de Paisagem, por exemplo, já é bastante utilizado por geógrafos(as) e, inclusive, em estudos que versam sobre Patrimônios Culturais (SOTRATTI, 2005). É importante notar que a UNESCO já reconhece a noção de Paisagem Cultural (FIGUEIREDO, 2013) ao ponto de utilizá-la sobre a cidade do Rio de Janeiro (RIBEIRO, 2019). Vale reforçar aqui que o conceito de Paisagem não é somente visual, engloba também perspectivas que envolvem a cultura na qual fora construída e até mesmo usos políticos (BESSE, 2014; RIBEIRO, 2019). Assim, a relação entre Paisagem e Patrimônio Industrial pode ser um caminho para aqueles que desejam trabalhar com o tema.

Já com o uso do conceito de Lugar, por exemplo, os Patrimônios Industriais poderiam ser entendidos enquanto espaços únicos, dotados de sentido e uma espécie de identidade singular perceptível somente por meio da experiência pessoal ou coletiva daqueles que os vivenciam (HOLZER, 1999; SOUZA, 2014). Logo, os trabalhos nesta 
abordagem poderiam entender como os Patrimônios Industriais acabaram afetando as sociedades no tempo em que estavam em pleno funcionamento e como hoje acabam sendo interpretados sob a ótica do tombamento por aqueles que os vivenciam. Topofobia, Topofilia (TUAN, 1983; 2012) e a perspectiva do Lugar de Memória (NORA, 1993) também podem ser evocadas aqui.

Por fim, para além dos conceitos-chave da Geografia, existem também outras perspectivas de abordagem que foram citadas por nós, neste trabalho (Geografia, Turismo e Patrimônio Industrial; Geografia, Patrimônio Industrial e Meio Ambiente etc.), e que poderiam ser exploradas pelos pesquisadores e pesquisadoras de nossa Disciplina. As possibilidades são muitas, não há limites ou restrições. Deixamos aqui, no final deste trabalho, uma espécie de convite ao leitor(a) para que possa "desbravar" este tema sob a ótica da Geografia.

\section{AGRADECIMENTOS}

Este trabalho foi desenvolvido com o apoio e auxílio da Coordenação de Aperfeiçoamento de Pessoal de Nível Superior (CAPES). Agradecemos também ao Grupo de Estudos e Pesquisas em Política e Território (GEOPPOL) da Universidade Federal do Rio de Janeiro (UFRJ), ao Programa de Pós-Graduação em Geografia da Universidade Federal do Rio de Janeiro (PPGG-UFRJ) e aos docentes do curso de Geografia da Conservação dessa mesma instituição.

\section{REFERÊNCIAS BIBLIOGRÁFICAS}

ABAD, Carlos. La Reutilización del Patrimonio Industrial como Recurso Turístico. Aproximación geográfica al turismo industrial. In: Treballs de la Societat Catalana de Geografia, n.57, 2004, p. 7-32.

BESSE, Jean-Marc. O Gosto do Mundo: exercícios de paisagem. Tradução: Annie Cambe. Rio de Janeiro: EdUERJ, 2014. 234p. 
CAPEL, Horacio. La Rehabilitación y el Uso del Patrimonio Histórico Industrial. In: Doc. Anàl. Geogr. n. 29, 1996, p.19-50

CARMO, Paulo. A Ideologia do Trabalho. $2^{\mathrm{a}}$ ed. São Paulo: Moderna, 2005. 144p.

CHOAY, Françoise. A Alegoria do Patrimônio. Tradução: Teresa Castro, Lisboa: Edições 70, 2000. 245 p.

CURY, Isabelle (org.). Cartas Patrimoniais. $3^{\mathrm{a}}$ ed. Rio de Janeiro: IPHAN, 2000.

DEZEN-KEMPTER, Eloísa. Patrimônio Industrial: em busca da sobrevivência. In: Anais do XXVI Simpósio Nacional de História - ANPUH. São Leopoldo - RS, Julho de 2007.

EDWARDS, J.; COIT, J. Mines and Quarries: Industrial Heritage Tourism. In: Annals of Tourism Research, Vol. 23, No. 2, 1996, p. 341-363.

ENGELS, Friedrich. A Situação da Classe Operária Trabalhadora na Inglaterra. Tradução: B.A. Schumann. São Paulo: Boitempo, 2010. 388 p.

FIGUEIREDO, Lauro. Perspectivas de Análise Geográfica do Patrimônio Cultural: algumas reflexões. In: Geografia Ensino \& Pesquisa, vol. 17, n. 1, 2013, p. 55-70.

FOLLIS, Fransérgio. Modernização Urbana na Belle Époque Paulista. São Paulo: Editora UNESP, 2004. 151p.

FONSECA, Maria. O Patrimônio em Processo: trajetória da política federal de conservação no Brasil. 2a ed. Rio de Janeiro: Editora UFRJ/MinC-IPHAN, 2005. 296 p.

FUNARI, Pedro; PELEGRINI, Sandra. Patrimônio Histórico e Cultural. $2^{\mathrm{a}}$ ed. Rio de Janeiro: Jorge Zahar Ed, 2009. 72 p.

GRAHAM, Brian; ASHWORTH, Greg; TURNBRIDGE, John. A Geography of Heritage: power, culture, economy. London: Arnold, 2000. 284 p. 
HARVEY, David. O Enigma do Capital: e as crises do capitalismo. Tradução de João Alexandre Peschanski. - São Paulo, SP: Boitempo, 2011. 235 p.

HOLZER, Werther. O Lugar na Geografia Humanista. In: Revista Território, Rio de Janeiro - RJ, ano IV, nº 7, 1999, p.67-78.

JONSEN-VERBEKE, Myriam. Industrial Heritage: a nexus for sustainable tourism development. In: Tourism Geographies: An International Journal of Tourism Space, Place and Environment, n.1, v.1, 1999, p. 70-85.

KÜHL, Beatriz. Patrimônio Industrial: algumas questões em aberto. In: Arq.Urb, v. 3, p.23-30, 2010.

LAFARGUE, Paul. O Direito à Preguiça. Tradução: Alain François. São Paulo: EDIPRO, 2016. 95 p.

LEAL, Cláudia. Patrimônio da Humanidade e Patrimônios Nacionais. In: A questão do nacional no IPHAN: Anais da III Oficina de Pesquisa/Coordenação-Geral de Pesquisa e Documentação. - Rio de Janeiro: IPHAN, DAF, Copedoc, 2010. p.47-60.

MENEGUELlo, Cristina. Patrimônio Industrial como Tema de Pesquisa. In: Anais do I Seminário Internacional História do Tempo Presente. Florianópolis: UDESC; ANPUH-SC; PPGH, 2011, p. 1819-1834.

MISATO, Marcelo; ZANIRATO, Silvia. O Passivo Ambiental da Industrialização Paulistana, Um Patrimônio Incômodo?. In: Anais do IV Congresso Internacional de História. Maringá: UEM, 2013.

NORA, Pierre. Entre Memória e História: a problemática dos lugares. Tradução: Yara Khoury. In: Projeto História. Revista do Programa de Estudos Pós-Graduados de História, v. 10, 1993, p. 7-28.

OLIVEIRA, Eduardo. A Cultura Industrial como Herança: questões sobre o reconhecimento de um patrimônio da industrialização "tardia" no Brasil. In: Revista Oculum ens., Campinas, n. 14(2), 2017, p. 311-330. 
POZO, Paz. Patrimonio Industrial y Cultura del Territorio. In: Boletín de la A.G.E., n. ${ }^{\text {o }}$ 34, 2002, p. $213-227$

POZO, Paz; GONZÁLEZ, Pablo. Industrial Heritage and Place Identity in Spain: from monuments to landscapes. In: The Geographical Review, n.102, v.4, 2012, p. 446-464.

RAMOS, Paulo. Recuperar um Símbolo do Passado: o "Arco" de Euston, em Londres. Património, Vandalismo e Arqueologia Industrial. In: Al-madam, n.21, 2017. p.142-146.

RIBEIRO, Rafael Winter. Gestão da Paisagem, Gestão da Cidade: quais os legados do Rio de Janeiro para o Patrimônio Mundial?. In: Revista CPC, n.14 (27), 2019, p.144166.

RIX, Michael. Industrial Archaelogy. In: The Amauter Historian, vol. 2, n. 8, 1955, p. 225-229.

ROSA, Carolina. O Patrimônio Industrial: a construção de uma nova tipologia de patrimônio. In: Anais do XXVI Simpósio Nacional de História - ANPUH. São Paulo, Julho de 2011.

RUDD, Michelle; DAVIS, James. Industrial Heritage Tourism at the Bingham Canyon Copper Mine. In: Journal of Travel Research, v. 36, 1998, p. 85-89.

SCIFONI, Simone. Tombamento e Participação Social: Experiência da Vila Maria Zélia, São Paulo - SP. In: Revista CPC, São Paulo, n.22, 2017, p.176-192.

SOTRATTI, Marcelo. Pelas Ladeiras do Pelo: a requalificação urbana como afirmação de um produto turistico. Dissertação (mestrado) - Universidade Estadual de Campinas, Instituto de Geociências, Campinas - SP, 2005. 396p.

SOUZA, Marcelo Lopes de. Os Conceitos Fundamentais da Pesquisa Sócio-Espacial. $3^{\mathrm{a}}$ Ed. Rio de Janeiro: Bertrand Brasil, 2016. 320 p.

SOCIEDADE DAS NAÇÕES. Carta de Atenas. In: CURY, Isabelle (org.). Cartas Patrimoniais. $3^{\mathrm{a}}$ ed. Rio de Janeiro: IPHAN, 2000. 
TICCIH - The International Committee for the Conservation of the Industrial Heritage. Carta de Nizhny Tagil sobre o Patrimônio Industrial, 2003. Disponível em:

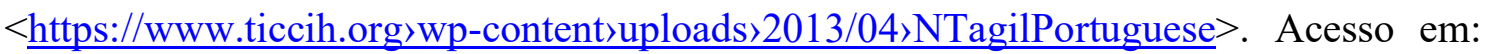
10 de Setembro de 2019.

TUAN, Yi-Fu. Espaço e Lugar: a perspectiva da experiência. Tradução: Lívia de Oliveira. São Paulo: Difel, 1983. 250p.

- Topofilia: um estudo da percepção, atitudes e valores do meio ambiente. Tradução: Lívia de Oliveira. São Paulo: Difel, 2012. 342p.

UNESCO - Organização das Nações Unidas para a Educação, a Ciência e a Cultura. Convenção sobre a Proteção do Patrimônio Mundial, Cultural e Natural, 1972. Disponível em: <https://whc.unesco.org〉archive>convention-pt $>$. Acesso em: $10 \mathrm{de}$ Setembro de 2019. 